\title{
THE EFFECT OF INTEGRATED THEMATIC TEACHING MATERIALS USING THE CONTEXTUAL TEACHING AND LEARNING APPROACH TO THE LEARNING OUTCOMES OF ELEMENTARY SCHOOL STUDENTS
}

\author{
Dewi Lusiana ${ }^{1}$, Taufina ${ }^{2}$ \\ ${ }^{1,2}$ Universitas Negeri Padang, Padang, Indonesia \\ 1dewilusiana967@gmail.com,${ }^{2}$ taufina@fip.unp.ac.id
}

\begin{abstract}
This study aims to determine the effect of integrated thematic teaching materials using a Contextual Teaching and Learning (CTL) approach for elementary school students. This research was an experimental study using a post only test research design. The procedure of this study consisted of a prerequisite test and a hypothesis test. The prerequisite test consisted of tests of normality and homogeneity and the hypothesis test consisted of the T test. The calculation results found that the $t_{\text {count }}$ of 12.2023 and $t t_{\text {able }} 11.66895$ at the level of significance $\alpha=0.05$ because $t_{\text {count }}$ was larger than $t t_{\text {able }}$ then $H_{o}$ was rejected, and $H_{a}$ was accepted. So it can be concluded that there was a significant influence on the use of thematic teaching materials using CTL on the learning outcomes of elementary school students. The implication of this research was that it can be used as a reference in the learning process in elementary schools.
\end{abstract}

Keywords: CTL, elementary school, teaching material

\section{PENGARUH PENGUNAAN BAHAN AJAR TEMATIK TERPADU MENGGUNAKAN PENDEKATAN CONTEXTUAL TEACHING AND LEARNING TERHADAP HASIL BELAJAR SISWA SEKOLAH DASAR}

\begin{abstract}
ABSTRAK
Penelitian ini bertujuan untuk mengetahui pengaruh penggunaan bahan ajar tematik terpadu menggunakan pendekatan Contextual Teaching and Learning (CTL) untuk siswa sekolah dasar. Penelitian ini merupakan penelitian eksperimen dengan menggunakan desian penelitian post only test. Prosedur penelitian ini terdiri dari uji prasyarat dan uji hipotesis. Uji prasyarat terdiri dari uji normalitas dan homogenitas dan uji hipotesis terdiri dari uji T. Hasil perhitungan ditemukan bahwa nilai $\mathrm{t}_{\text {hitung }}$ sebesar 12.2023 dan $\mathrm{t}_{\text {tabel }} 11.68595$ pada taraf signifikasi $\alpha=0.05$ dikarenakan $\mathrm{t}_{\text {hitung }}$ besar dari $\mathrm{t}$ tabel maka $\mathrm{H}_{\mathrm{o}}$ ditolak, dan $\mathrm{H}_{\mathrm{a}}$ diterima. Sehingga dapat disimpulkan bahwa ada pengaruh yang signifikan pada penggunaan bahan ajar tematik menggunakan CTL terhadap hasil belajar siswa sekolah dasar. Implikasi penelitian ini adalah dapat dijadikan referensi dalam proses pembelajaran disekolah dasar di Indonesia.
\end{abstract}

Kata Kunci: CTL, sekolah dasar, bahan ajar

\begin{tabular}{|c|c|c|}
\hline Submitted & Accepted & Published \\
\hline 11 Mei 2020 & 14 Juli 2020 & 24 Juli 2020 \\
\hline
\end{tabular}

\begin{tabular}{|l|c|c|c|}
\hline Citation & $:$ & $\begin{array}{c}\text { Lusiana, D., \& Taufina. (2020). The Effect of Integrated Thematic Teaching Materials Using The Contextual Teaching } \\
\text { and Learning Approach to the Learning Outcomes of Elementary School Students. Jurnal PAJAR (Pendidikan } \\
\text { dan Pengajaran), 4(4), 764-770. DOI : http://dx.doi.org/10.33578/pjr.v4i2.8020. }\end{array}$ \\
\hline
\end{tabular}

\section{PENDAHULUAN}

Sekolah dasar merupakan jenjang pendidikan pertama bagi siswa, (Kenedi et al, 2019). Sebagai jenjang pertama yang dilalui oleh siswa, maka sekolah dasar memiliki peranan yang besar dalam proses pentransferan ilmu pengetahuan dan teknologi, (Hamimah, Kenedi, Zuryanty, 2020). Sekolah dasar dalam fungsinya sebagai lembaga pendidikan formal memiliki tanggung jawab untuk mampu mengembangankan ilmu, pengetahuan dan keterampilan dasar yang berguna bagi siswa dalam proses kehidupan sehari-hari, (Hamimah, 2020). Ilmu pengetahuan dan keterampilan dasar inilah yang akan dikembangkan siswa dalam proses pendidikan 
lanjutan lainnya. Oleh sebab itu, pembelajaran disekolah dasar harus dilaksanakan dengan maksimal agar tercapainya tujuan dan fungsi sekolah dasar tersebut.

Pembelajaran di sekolah dasar harus disesuaikan dengan tingkatan perkembangan anak usia sekolah dasar, (Kiswanto, 2017). Siswa sekolah dasar merupakan anak yang berada pada masa operasional kongkret. Pada masa operasional kongkret siswa harus belajar dari hal-hal yang bersifat nyata, (Kenedi, 2019). Artinya pada masa ini siswa harus belajar dari benda-benda yang dapat disentuh dan diamati langsung. Hal ini bertujuan agar siswa dapat dengan mudah mempelajari materi maupun informasi yang diberikan secara menyeluruh. selain itu pembelajaran pada anak usia sekolah dasar juga dapat dilakukan dengan mengaitkan pembelajaran dengan pengalaman langsung siswa. Artinya setiap pembelajaran harus dikaitkan dengan peristiwa yang pernah dialami oleh siswa. Hal ini juga bertujuan agar siswa dapat memahami informasi secara baik dikarenakan telah mengalami peristiwa tersebut. Oleh sebab itu pembelajaran disekolah dasar berbeda jauh dengan proses pembelajaran lainnya. Sehingga guru sekolah dasar memiliki tanggung jawab yang besar untuk mampu mengembangkan pembelajaran yang sesuai dengan karakteristik siswa sekola dasar tersebut.

Guru sekolah dasar memiliki peranan penting dalam proses pembelajaran disekolah dasar, (Sumual and Ali, 2017). Guru harus mampu merancang pembelajaran yang dapat mencapai tujuan pembelajaran secara maksimal dengan memperhatikan karakteristik siswa sekolah dasar dan karakteristik pembelajaran di sekolah dasar, (Helsa et al, 2019). Pembelajaran disekolah dasar pada saat sekarang ini menggunakan pendekatan tematik terpadu, (Hamimah et al, 2019). Artinya pembelajaran disekolah dasar menggabungkan berbagi macam disiplin ilmu menjadi satu bagian yang memiliki tema. Proses pembelajaran ini lah yang menjadi acuan guru dalam mengembangan pembelajaran di sekolah dasar. Namun berdasarkan analisis peneliti terhadap hasil observasi yang peneliti lakukan di SDN 14 Nan Duo Kabupaten Pasaman Barat terlihat bahwa hasil belajar siswa kelas $\mathrm{V}$ berkategori rendah yang diakibatkan proses pembelajaran yang dilaksanakan oleh guru tidak sesuai dengan karakteristik siswa sekolah dasar. Oleh sebab itu, maka peneliti berdiskusi dengan guru kelas untuk mencari solusi permasalahan tersebut. Diskusi ini dilaksanakan pada tanggal 13 Februari 2020.

Dari hasil diskusi tersebut maka peneliti sepakat untuk menciptakan inovasi pembelajaran berupa pengembangan bahan ajar. Hal ini dikarenakan bahan ajar yang digunakan belum sesuai dengan karakristik siswa sekolah dasar. Bahan ajar yang digunakan oleh guru belum mampu membuat pembelajaran menjadi bermakna. Bahan ajar yang digunakan masih sekedar penyajian informasi dan materi tanpa mencipatkan pembelajaran mandiri dengan mengaitkan pengalaman siswa. bahan ajar yang ada juga tidak menfasilitasi siswa untuk dapat belajar baik secara mandiri maupun kolaborasi. Selain itu bahan ajar yang digunakan sekolah juga tidak menyajikan materi yang dapat mengembangkan kemampuan berpikir kritis dan kreatif siswa yang merupakan salah satu kemampuan yang sangat diperlukan siswa dalam proses kehidupan sehari-hari. Oleh sebab itu, maka perlunya pengembangan bahan ajar yang mampu mengatasi permasalahan tersebut.

Pengambangan bahan ajar dikembangkan berdasarkan proses pembelajaran contextual teaching and learning (CTL). CTL merupakan proses pembelajaran yang memfokuskan kepada proses pembelajaran yang berhubungan dengan kehidupan nyata siswa yang menyajikan pembelajaran menjadi bermakna, mengembangkan pembelajaran yang mampu meningkatkan kemandirian belajar dan juga kolaborasi siswa serta dapat meningkatkan kemampuan berpikir kritis dan kreatif siswa. oleh sebab itu pengembangan bahan ajar menggunakan CTL dianggap mampu untuk mengatasi permasalahan sebelumnya, (Johnson, 2002).

Penelitian sebelumnya peneliti telah mengembangkan bahan ajar berbasis CTL untuk siswa sekolah dasar dan telah dinyatakan valid dan layak untuk digunakan. Maka untuk mengetahui keefektifan bahan ajar yang telah dikembangkan maka diadakan penelitian lebih lanjut. Maka 
tujuan penelitian ini adalah untuk mengetahui pengaruh pengunaan bahan ajar tematik terpadu menggunakan pendekatan contektual teaching and learning untuk siswa sekolah dasar. Penelitian ini penting dilaksanakan karena bahan ajar yang dikembangakan telah dinyatakan valid oleh pakar ahli dan perlu pembuktian secata kuantitatif bahwa bahan ajar berbasis CTL ini efektif untuk diterapkan pada proses pembelajaran. Hal ini bertujuan agar bahan ajar berbasis CTL ini dapat memberikan dampak yang luas terhadap kualitas pembelajaran disekolah dasar.

\section{METODE PENELITIAN}

Penelitian ini merupakan penelitian eksperimen dengan menggunakan desian penelitian

post only test. Desain penelitian dapat dilihat pada tabel di bawah ini.

Tabel 1. Desain Penelitian

\begin{tabular}{ccc}
\hline Kelompok & Perlakuan & Tes Akhir \\
\hline Eksperimen & $\mathrm{X}$ & $\mathrm{O}$ \\
Kontrol & - & $\mathrm{O}$ \\
\hline
\end{tabular}

Keterangan

$\mathrm{O}=$ Tes tertulis (Tes Akhir)

$\mathrm{X}=$ Bahan ajar menggunakan CTL

Sampel penelitian yaitu siswa kelas V 14 Luhak Nan tuo yang terdiri dari 40 siswa yang dibagi menjadi dua kelas. Penelitian ini menggunakan dua kelas yaitu kelas eksperimen dan kelas kontrol. Kelas eksperimen merupakan kelas yang diberikan perlakuan dengan melaksanakan proses pembelajaran menggunakan bahan ajar berbasis CTL dan kelas kontrol merupakan kelas yang menggunakan bahan ajar seperti biasa. Penelitian ini terdiri dari uji prasyarat dan uji hipotesis. Uji prasyarat terdiri dari uji normalitas dan uji homogenitas sedangkan uji hipotesis terdidir dari Uji $\mathrm{T}$ (Kenedi, 2019). Instrumen yang digunakan pada penelitian ini menggunakan soal tes. Pelaksanaan pembelajaran menggunakan bahan ajar berbasis CTL tertuang dalam RPP yang telah divalidasi oleh pakar ahli dan dinyatakan layak untuk dilaksanakan.

\section{HASIL DAN PEMBAHASAN}

Penelitian ini diawali dengan dan uji homogenitas. dilaksanakanya uji prasyarat yaitu uji normalitas

Tabel 2. Hasil Uji Normalitas Postest Kelas Ekperimen dan Kontrol

\begin{tabular}{cccccc}
\hline No & Kelas & $\mathbf{N}$ & L hitung & $\begin{array}{c}\text { L tabel } \\
\mathbf{\alpha ~ 0 , 0 5}\end{array}$ & Kesimpulan \\
\hline $\mathbf{1}$ & Eksperimen & 20 & 0.03252 & 0.190 & Data Normal \\
$\mathbf{2}$ & Kontrol & 20 & 0.04423 & 0.190 & Data Normal \\
\hline
\end{tabular}

Hasil uji normalitas posttest kelas eksperimen dan kelas kontrol dalam penelitian. Diketahui, Lhitung kelas eksperimen sebesar 0.03252 dan $\mathrm{L}$ hitung kelas kontrol sebesar 0.04423 dengan jumlah sampel masing-masing 20. Pada taraf signifikansi $\alpha=0.05$ didapat nilai $\mathrm{L}_{\text {tabel }}$ sebesar 0.190. Sehingga pada kelas eksperimen diperoleh $\mathrm{L}_{\text {hitung }}<\mathrm{L}_{\text {tabel }},(0.03252<0.190)$, dan untuk kelas kontrol juga diperoleh $\mathrm{L}_{\text {hitung }}<\mathrm{L}_{\text {tabel }}$ $(0.04423<0.190)$. Uji normalitas bertujuan untuk melihat apakah nilai residual terdistribusi normal atau tidak. Berdasarkan data tersebut terlihat 
bahwa data kelas eksperimen dan kelas kontrol adalah normal.
Selanjutnya adalah uji homogenitas. Uji homogenitas dapat dilihat pada tabel dibawah ini.

Tabel 3. Hasil Uji Homogenitas Posttest Kelas Eksperimen dan Kontrol

\begin{tabular}{lllllll}
\hline No & Kelas & $\mathbf{N}$ & Variansi & $\mathbf{F}_{\text {hitung }}$ & $\mathbf{F}_{\text {tabel }}$ & Kesimpulan \\
\hline $\mathbf{1}$ & Eksperimen & 20 & 184.721 & 1.1882 & 2.12 & Varian \\
$\mathbf{2}$ & Kontrol & 20 & 145.335 & & & Homogen \\
\hline
\end{tabular}

Hasil uji homogenitas posttest kelas eksperimen dan kelas kontrol dalam penelitian ini adalah, diketahui $\mathrm{F}$ hitung kelas eksperimen dan kelas kontrol sebesar 1.1882 dengan jumlah sampel masing-masing 20. Pada taraf signifikansi $\alpha=0,05$ didapat $F$ tabel 2.12 . Sehingga diperoleh $F$ hitung $<\mathrm{F}_{\text {tabel, }}$ yakni $(1.1882<2.12)$.

Dengan demikian, dapat disimpulkan bahwa data pada kelas eksperimen dan kelas kontrol memiliki varian yang homogen. Uji homogennitas dilakukan dengan menyelidik apakah kedua sampel berasal dari populasi dengan variansi yang sama atau tidak. Uji ini dilakukan untuk memastikan apakah asumsi homogenitas pada masing-masing kategori data sudah terpenuhi ataukan belum. Apabila asumsi homogenitasnya terbukti maka peneliti dapat melakukan pada tahap analisis data lanjutan. Akan tetapi apabila tidak terbukti maka peneliti harus melakukan pembetulan-pembetulan metodologis.

Langkah selanjutnya menggunakan uji hipotesis. Uji hipotesis dilakukan terhadap nilai posttest kelas eksperimen dan kelas kontrol. Berdasarkan uji prasyarat analisis data, data posttest untuk kedua kelompok berdistribusi normal dan memiliki varian yang homogen. Sehingga dapat dilakukan pengujian hipotesis dengan menggunakan uji t polled varian. Adapun hasil Uji T kelas eksperimen dan kelas kontrol sebagai berikut:

Tabel 4. Hasil Uji T Posttest Kelas Eksperimen dan Kelas Kontrol

\begin{tabular}{llccccl}
\hline No & Kelas & $\mathbf{N}$ & Mean & $\mathbf{T}_{\text {hitung }}$ & $\begin{array}{r}\mathbf{T}_{\text {tabel }} \\
\mathbf{0 , 0 5 / 2}\end{array}$ & Kesimpulan \\
\hline 1 & Eksperimen & 20 & 72.3 & 12.2023 & 11.6859 & Ha diterima \\
2 & Kontrol & 20 & 62.5 & & & H0 ditolak \\
\hline
\end{tabular}

Diketahui bahwa nilai $\mathrm{t}$ hitung sebesar 12.2023dan $\mathrm{t}_{\text {tabel }} 11.68595$ pada taraf signifikasi $\alpha$ $=0.05$. Karena $12.2023>11.68195$ maka Ho ditolak, dan $\mathrm{Ha}$ diterima. Sehingga dapat disimpulkan bahwa ada pengaruh yang signifikan pada penggunaan bahan ajar tematik menggunakan CTL terhadap hasil belajar siswa sekolah dasar.

Hasil temuan ini didukukung oleh penelitian sebelumnya. Penelitian Selvia dkk menyatakan bahwa telah dikembangkanya bahan ajar fisika berbasis CTL yang berdampak positif terhadap hasil belajar siswa SMA, (Selvia et al, 2017). Penelitian Amar dkk juga menyatakan bahwa terjadinya peningkatan aktivitas dan hasil belajar sejarah Indonesia mahasiswa sejarah dengan menggunakan bahan ajar berbasis CTL,
(Amar, Rasyad, and Sulastri, 2014). Selain itu penelitian yang dilakukan oleh Putri dkk menyatakan bahwa telah dikembangkanya bahan ajar yang materi lingkungan untuk siswa SMA yag valid, praktis dan efektif, (Putri et al, 2018). Penelitian Sukmawati juga menyatakan bahwa telah dikembangkanya bahan ajar biologi berbasis CTL yang efektif bagi siswa SMA, (Sukmawati, 2015). Dari penelitian tersebut terlihat bahwa bahan ajar yang dikembangankan dengan menggunakan CTL mampu berpengaruh terhadap proses pembelajaran siswa. Namun temuan penelitian ini berbeda dari penelitian sebelumnya yaitu bahan ajar yang dikembangkan merupakan bahan ajar tematik terpadu yang dikembangkan untuk siswa sekolah dasar yanh secara khusus 
proses pembelajaranya berbeda dengan proses pembelajaran pada tingkatan pendidikan lainnya. Penelitian ini menyatakan bahwa siswa yang belajar dengan bahan ajar tematik terpadu dengan menggunakan pendekatan CTL memiliki pengaruh positif terhadap hasil belajar siswa.

Bahan ajar merupakan segala perangkat materi yang disusun dengan sengaja baik secara tertulis maupun tidak tertulis yang memungkin kan terciptanya suasana belajar yang kondusif, (Ramdani, 2012). Pada penelitian ini meenyatakan bahwa penggunaan bahan ajar berpengaruh terhadap hasil belajar siswa. Bahan ajar dalam proses pembelajaran memiliki fungsi yang banyak. Bahan ajar dalam proses pembelajaran klasikal berfungsi sebagai sumber informasi dalam proses pembelajaran dan sebagai sarana pendukung proses pembelajaran, (Susarno and Wetan, 2010). Bahan ajar dalam penelitian ini dapat dijadikan sebagai sumber belajar oleh siswa. Dengan penyajian pembelajaran yang disesuaikan dengan karakterisitik siswa, bahan ajar ini mampu membimbing siswa untuk mengembangkan proses pembelajaran yang memungkinkan siswa untuk memahami infromasi dan materi yang disajikan secara menyeluruh. Selain itu bahan ajar dalam proses pembelajaran individu juga berfungsi sebagai sarana utama bagi individu untuk melaksanakan proses pembelajaran mandiri dan sarana pendukung bagi siswa lainnya, (Zuriah et al, 2016). Pada penelitian ini bahan ajar dapat dijadikan oleh siswa sebagai sarana utama untuk belajaran mandiri dalam menemukan infromasi baik di sekolah maupun diluar sekolah. Selain itu bahan ajar juga berfungsi dalam proses pembelajaran berkelompok sebagai sarana dalam memfasilitasi penyajian infromasi yang digunakan dalam proses kolaborasi antar sesama siswa, (Muchyidin, 2017). Penelitian ini membuktikan bahwa bahan ajar yang digunakan mampu menyajikan kegaiatan kolaborasi siswa dalam menemukan informasi.
Bahan ajar yang dikembangkan diselaraskan dengan pendekatan CTL. CTL merupakan pendekatan pembelajaran yang disusun dengan memperhatikan proses pembelajaran yang mengkaji keterlibatan siswa dalam belajar dengan cara menemukan informasi secara menyeluruh melalui pengalaman siswa pada kehidupan seharihari (Sears, 2002). Pengembangan bahan ajar menggunakan CTL ini membutikan bahwa adanya dampak positif terhadap hasil belajar siswa sekolah dasar. Pada penelitian ini terlihat bahwa siswa dapat mengatur proses pembelajaran yang diinginkan baik secara individu maupun kelompok melalui kegiatan yang telah diatur dalam bahan ajar. Hal ini dikarenakan salah satu karakteristik CTLyaitu Making meaningful connections yang artinya bahwa siswa memiliki kebebasan untuk membuat hubungang dengan siapapun dalam proses pembelajaran, (Halik, 2016). Selain itu siswa yang menggunakan bahan ajar ini dilatih untuk menemukan informasi dengan cara menghubungkan dengan kehidupan nyata mereka. Hal ini sesuai dengan salah satu karakteristik CTL yaitu Doing significant work yang artinya mampu melakukan pekerjaan penting dengan cara menghubunkan informasi dari kehidupan nyata siswa, (Qudsy et al, 2017). Pada penelitian ini terlihat juga bahwa siswa mampu melaksanakan pembelajaran secara mandiri dikarenakan bahan ajar difasilitasi dengan kegiatan individu. Hal ini dikarenakan karakteristik CTL yaitu CTL bersifat Self-regulated learning yang artinya adalah mampu belajar dengan mengatur diri sendiri, (Anwar, 2019). Selain itu penelitian ini memfasilitasi siswa untuk dapat menemukan informasi melalui kegiatan kerjasama. Hal ini dikarenakan kerjasama merupakan salah satu karakteristik CTL, (Selvianiresa \& Prabawanto, 2017) . Faktor-faktor inilah yang mempengaruhi adanya dampak CTL terhadap pengembangan bahan aja yang berpengaruh terhadap hasil belajar siswa sekolah dasar. 


\section{SIMPULAN DAN REKOMENDASI}

Hasil perhitungan ditemukan bahwa nilai t hitung sebesar 12.2023 dan $t_{\text {tabel }} 11.68595$ pada taraf signifikasi $\alpha=0,05$ dikarenakan $t_{\text {hitung }}$ besar dari t tabel maka Ho ditolak, dan Ha diterima. Sehingga dapat disimpulkan bahwa ada pengaruh yang signifikan pada penggunaan bahan ajar

\section{DAFTAR PUSTAKA}

Amar, S., Rasyad, A., \& Sulastri, A. (2014). Meningkatkan Aktifitas dan Hasil Belajar Sejarah Indonesia I Melalui Model CTL Berbantuan Bahan Ajar. Educatio, 9(2), 181-200.

Anwar, S., Pujiastuti, H., \& Mutaqin, A. (2019). Pengaruh Contextual Teaching And Learning Dan Self Regulated Learning Terhadap Kemampuan Koneksi Matematis. Prima: Jurnal Pendidikan Matematika, 3(2), 116-133.

Halik, N. (2016). Contextual Teaching and Learning Method to Third Year Students of MTsN Balang-Balang Kabupaten Gowa. ETERNAL (English, Teaching, Learning, and Research Journal), 2(2), 147166.

Hamimah, H., Kenedi, A. K., \& Zuryanty, Z. (2020). Efforts To Increase High-Level Thinking Ability Using Open-Ended Approaches. Jurnal Pajar (Pendidikan dan Pengajaran), 4(2), 296-302.

Hamimah, H., Kenedi, A. K., Zuryanty, Z., \& Nelliarti, N. (2020) Peningkatan Kemampuan Berpikir Kritis Menggunakan Model Problem-Based Learning. Primary: Jurnal Pendidikan Guru Sekolah Dasar, 9(2), 173-184

Hamimah, H., Zuryanty, Z., Kenedi, A. K., \& Nelliarti, N. (2019). The Development of the 2013 Student Curriculum Book Based on Thinking Actively in Social Context for Elementary School Students. Al Ibtida: Jurnal Pendidikan Guru MI, 6(2), 159-176.

Helsa, Y. Y., Helsa, Y., Ariani, Y., \& Kenedi, A. K. (2019, December). Digital Class Model in Mathematics Learning in Elementary tematik menggunakan CTL terhadap hasil belajar siswa sekolah dasar. Penelitian ini menyarankan agar guru SD dapat mengembangkan bahan ajar menggunakan CTL untuk meningkatkan hasil belajar siswa sekolah dasar.

School Using Social Learning Network Schoology. In 5th International Conference on Education and Technology (ICET 2019). Atlantis Press.

Johnson, E. B. (2002). Contextual teaching and learning: What it is and why it's here to stay.New York: Corwin Press.

Kenedi, A. K. (2019, December). Peningkatan kemampuan koneksi matematis siswa Sekolah Dasar melalui model Project Based Learning. In Seminar Nasional Peningkatan Mutu Pendidikan (Vol. 1, No. 1).

Kenedi, A. K., Eliyasni, R., \& Fransyaigu, R. (2019, December). Jigsaw using animation media for elementary school. In Journal of Physics: Conference Series (Vol. 1424, No. 1, p. 012027). IOP Publishing.

Kenedi, A. K., Helsa, Y., Ariani, Y., Zainil, M., \& Hendri, S. (2019). Mathematical Connection of Elementary School Students to Solve Mathematical Problems. Journal on Mathematics Education, 10(1), 69-80.

Kiswanto, A. (2017, September). The Effect Of Learning Methods And The Ability Of Students Think Logically To The Learning Outcomes On Natural Sciences Of Grade IvS Student. In 9th International Conference for Science Educators and Teachers (ICSET 2017). Atlantis Press.

Muchyidin, A. (2017). Pengaruh Penggunaan Bahan Ajar Matematika Bersuplemen Komik Terhadap Kemandirian Belajar Siswa. Eduma: Mathematics Education Learning and Teaching, 6(1), 43-51.

Putri, A. E., Misdalina, M., \& Oktavia, M. (2018). Pengembangan Bahan Ajar Materi Lingkungan Hidup Kelas XI Menggunakan 
Model Pembelajaran Ctl Di SMA Negeri 2 Mesuji. JURNAL SWARNABHUMI: Jurnal Geografi dan Pembelajaran Geografi, 3(1), $1-8$.

Qudsyi, H., Wijaya, H. E., \& Widiasmara, N. (2017, October). Effectiveness of Contextual Teaching and Learning (CTL) to Improve Students Achievement and Students' SelfEfficacy in Cognitive Psychology Course. In International Conference on Learning Innovation (ICLI 2017). Atlantis Press.

Ramdani, Y. (2012). Pengembangan Instrumen dan Bahan Ajar untuk Meningkatkan Kemampuan Komunikasi, Penalaran, dan Koneksi Matematis dalam Konsep Integral. Jurnal Penelitian Pendidikan, 13(1), 44-52.

Santoso, S. (2010). Statistik multivariat. Jakarta: Elex Media Komputindo.

Sears, S. J. (2002). Contextual teaching and learning: A primer for effective instruction. New York: Phi Delta Kappa International.

Selvia, M., Arifuddin, M., \& Mahardika, A. I. (2017). Pengembangan Bahan Ajar Fisika Sma Topik Fluida Berorientasi Masalah Lahan Basah melalui Pendekatan Contextual Teaching and Learning (CTL). Berkala Ilmiah Pendidikan Fisika, 5(2), 213-222.

Selvianiresa, D., \& Prabawanto, S. (2017, September). Contextual Teaching and Learning Approach of Mathematics in Primary Schools. In Journal of Physics: Conference Series(Vol. 895, No. 1, p. 012171). IOP Publishing.

Sukmawati, F. (2015). Pengembangan Bahan Ajar Biologi Berbasis Contextual Teaching Learning untuk Mengefektifkan Pembelajaran bagi Siswa SMA. FENOMENA, 7(1), 145-154.

Sumual, M. Z. I., \& Ali, M. (2017). Evaluation of Primary School Teachers' Competence in Implementing 2013 Curriculum: a Study in Tomohon City. Journal of Education and Learning, 11(3), 343-350.

Susarno, L. H., \& Wetan, K. L. (2010). Strategi Penyampaian Bahan Ajaran Melalui Pemanfaatan Metode dan Media dalam
Proses Pembelajaran. Jurnal Teknologi Pendidikan, 10(1), 1-7.

Zuriah, N., Sunaryo, H., \& Yusuf, N. (2016). IbM guzru dalam Pengembangan Bahan Ajar Kreatif Inovatif Berbasis Potensi Lokal. Jurnal Dedikasi, 13, 1-10. 